\title{
Inhibition of platelet-derived growth factor receptor synergistically increases the pharmacological effect of tamoxifen in estrogen receptor $\alpha$ positive breast cancer
}

\author{
SANGMIN KIM ${ }^{1}$, DAEUN YOU ${ }^{1,2}$, YISUN JEONG $^{1,2}$, SUN YOUNG YOON ${ }^{1,2}$, \\ SUNG A KIM ${ }^{1,2}$ and JEONG EON LEE ${ }^{1-3}$ \\ ${ }^{1}$ Department of Breast Cancer Center, Samsung Medical Center; ${ }^{2}$ Department of Health Sciences and Technology, \\ SAIHST, Sungkyunkwan University; ${ }^{3}$ Department of Surgery, Samsung Medical Center, Sungkyunkwan \\ University School of Medicine, Gangnam-gu, Seoul 06351, Republic of Korea
}

Received July 24, 2020; Accepted February 1, 2021

DOI: $10.3892 / \mathrm{ol} .2021 .12555$

\begin{abstract}
The platelet-derived growth factor (PDGF) family, a complex and imperative group of proangiogenic factors, acts as strong cell growth chemokines and is essential for the progression of malignancy in humans. In the present study, it was observed that aberrant PDGFB expression is associated with survival rates in patients with estrogen receptor-positive $\left(\mathrm{ER}^{+}\right)$breast cancer unlike other subtypes, including PDGFA, PDGFC and PDGFD. Accordingly, the effect of specific PDGF receptor (PDGFR) inhibitors on ER- $\alpha^{+}$breast cancer cells was investigated. To block the PDGF-BB signaling pathway, PDGFR inhibitors (sunitinib or ponatinib) were employed. Sunitinib and ponatinib were found to arrest the cell cycle at the G0-G1 phase. In addition, the two PDGFR inhibitors were revealed to significantly inhibit cell growth and decrease the expression of matrix metalloproteinase-1, which is one of the metastasis-related genes. Finally, the combined effects of the two PDGFR inhibitors with tamoxifen were investigated. The results demonstrated that the combination of two PDGFR inhibitors with tamoxifen inhibited the growth of cells more consistently, compared with the effect mediated by tamoxifen alone. Therefore, it is proposed that PDGFR inhibitors, including sunitinib and ponatinib, should be applied effectively to treat ER- $\alpha^{+}$breast cancer.
\end{abstract}

Correspondence to: Dr Sangmin Kim, Department of Breast Cancer Center, Samsung Medical Center, 81 Irwon-ro, Gangnam-gu, Seoul 06351, Republic of Korea

E-mail: sangmin3005.kim@samsung.com

Dr Jeong Eon Lee, Department of Health Sciences and Technology, SAIHST, Sungkyunkwan University, 81 Irwon-ro, Gangnam-gu, Seoul 06351, Republic of Korea

E-mail: paojlus@hanmail.net

Key words: platelet-derived growth factor-BB, platelet-derived growth factor receptor $\alpha$, platelet-derived growth factor receptor $\beta$, cell cycle arrest, estrogen receptor- $\alpha^{+}$breast cance

\section{Introduction}

Approximately $70 \%$ of breast carcinomas express estrogen receptor (ER) and progesterone receptor (PR), and these tumors are subclassified as luminal A (Lum A) or B (Lum B) according to the rate of proliferation $(1,2)$. Endocrine therapy has become one of the most important treatments for breast cancer patients. Tamoxifen is a selective ER modulator that acts as an ER antagonist in the breast (2). The majority of patients with $\mathrm{ER}^{+}$breast cancer undergo adjuvant endocrine therapy but $\sim 20-30 \%$ of them eventually experience recurrence with distant metastasis (3). Therefore, despite improvements in treatment, therapy resistance remains a major clinical problem $(3,4)$. Numerous researchers around the world are aiming to identify novel targets to improve treatment efficiency for endocrine therapy-resistant patients.

Platelet-derived growth factor (PDGF) is a critical regulator of cell proliferation, migration and angiogenesis in various cells (4). The PDGF family consists of five isoforms (PDGF-AA, $-\mathrm{BB},-\mathrm{AB},-\mathrm{CC}$, and -DD) and differentially binds to two receptor tyrosine kinases (RTKs), PDGFR $\alpha$ and PDGFR $\beta$ (5). The different receptors bind with the ligands with different affinities. PDGFR $\alpha$ preferentially binds with PDGF-A, -B, and -C, whereas PDGFR $\beta$ binds with PDGF-B and -D $(6,7)$. Activated PDGFR $\alpha$ and $\beta$ subsequently trigger downstream signal transduction pathways, including extracellular signal-regulated kinase 1/2 (ERK) and phosphatidylinositol 3-kinase (PI3K)/AKT for promoting cell proliferation, migration and survival (8). In particular, breast cancers with high PDGFR $\alpha$ expression are associated with lymph node metastasis and human epidermal growth factor receptor 2 (HER2) positivity (9).

In the present study, the clinical significance of PDGFB expression in $\mathrm{ER}^{+}$breast cancer was investigated and the pharmacological effects of two PDGFR inhibitors (sunitinib and ponatinib) and/or tamoxifen in ER- $\alpha^{+}$breast cancer cells was also investigated.

\section{Materials and methods}

Reagents. Charcoal-stripped fetal bovine serum (FBS) was purchased from Thermo Fisher Scientific Inc.. 
4-hydroxytamoxifen (4-OHT; the active metabolite of tamoxifen) was purchased from Sigma-Aldrich (Merck KGaA). Anti-PDGFB (cat. no.sc-365805; dilution, 1:1,000) and ER- $\alpha$ (cat. no. sc8002; dilution, 1:1,000) antibodies were purchased from Santa Cruz Biotechnology, Inc. Anti-MMP-1 antibody (cat. no. ab137332; dilution, 1:1,000) was purchased from Abcam. $\beta$-actin (cat.no.LF-PA0207; dilution, 1:2,000) antibody was purchased from Ab Frontier. Total (t)-, phosphor (p)-ERK (cat. nos. 9102 (t); and 4370 (p); dilution, 1:1,000) and STAT3 (cat. nos. 4904 (t) and 9145 (p); dilution, 1:1,000) antibodies were purchased from Cell Signaling Technology, Inc. Goat anti-rabbit (cat. no. sc-2004; dilution, 1:2,000) and anti-mouse (cat. no. sc-2005; dilution, 1:2,000) IgG-HRP secondary antibodies were purchased from Santa Cruz Biotechnology, Inc.

Cell culture. Breast cancer ZR751, BT474 and T47D cell lines were cultured in RPMI-1640 medium (Thermo Fisher Scientific, Inc.), supplemented with $10 \%$ fetal bovine serum (FBS; HyClone), $2 \mathrm{mM}$ glutamine, $100 \mathrm{IU} / \mathrm{ml}$ penicillin and $100 \mu \mathrm{g} / \mathrm{ml}$ streptomycin. Breast cancer MCF-7 cells were grown in Dulbecco's modified Eagle's medium (DMEM; Life Technologies; Thermo Fisher Scientific, Inc.) under the same conditions. All the cells were maintained at $37^{\circ} \mathrm{C}$ in a humidified incubator with $5 \% \mathrm{CO}_{2}$. Cell culture medium was collected to confirm the existence of mycoplasma. The absence of mycoplasma was checked using the EZ-PCR Mycoplasma Test kit (Biological Industries).

Analysis of public database. The prognostic value of PDGFB mRNA expression in $\mathrm{ER}^{+}$breast cancer was assessed according to DFS/DMFS using the Kaplan-Meier plotter database (https://kmplot.com/analysis/index. php? $\mathrm{p}=$ service \& cancer $=$ breast $)(10)$. DFS $(n=2061)$, DMFS $(n=664)$ and OS $(n=548)$ were analyzed in patients with $\mathrm{ER}^{+}$ breast cancer using Kaplan-Meier survival plots. Log-rank P-values and HRs with $95 \%$ confidence intervals were determined on the webpage.

Western blotting. The cells were lyzed using PRO-PREP ${ }^{\mathrm{TM}}$ Protein Extraction Solution (Intron Biotechnology, Inc.) and centrifuged $(16,100 \mathrm{x} \mathrm{g}$ for $15 \mathrm{~min})$. The levels of protein expression were assessed as previously described $(11,12)$. In brief, isolated proteins were dissolved in $5 \mathrm{X}$ sample buffer and boiled for $5 \mathrm{~min}$. An equal amount ( $30 \mu \mathrm{g} /$ lane) of total protein was electrophoresed in $10 \%$ SDS-PAGE gel. Separated proteins were transferred onto PVDF membranes (GE Healthcare) and blocked with $10 \%$ skimmed milk in Tris-buffered saline with $0.01 \%$ Tween-20 (TBST) buffer for $15 \mathrm{~min}$ at room temperature (RT). Blots were incubated with anti-PDGFB, ER- $\alpha$, PARP-1, pro-, cleaved-caspase- 3 or $\beta$-actin antibodies in $1 \%$ TBST buffer at $4^{\circ} \mathrm{C}$ overnight. Blots were washed 3-4 times in TBST and incubated with appropriate secondary antibodies in TBST buffer for $1 \mathrm{~h}$ at RT. After $1 \mathrm{~h}$, blots were washed 3-4 times with TBST buffer. Protein expression bands were visualized using the ECL ${ }^{\mathrm{TM}}$ Western Blotting Detection Reagent (GE Healthcare).

Reverse transcription-quantitative polymerase chain reaction (RT-qPCR). Total RNA extracted from human breast cancer cells using TRIzol reagent (Thermo Fisher Scientific, Inc.) were used for RT-qPCR analysis. In brief, $1 \mu \mathrm{g}$ total RNA from each sample was reverse transcribed (denaturation, $94^{\circ} \mathrm{C}$ for $30 \mathrm{sec}$; annealing $58^{\circ} \mathrm{C}$ for $30 \mathrm{sec}$ and extension $72^{\circ} \mathrm{C}$ for $45 \mathrm{sec}$ ) using a RevertAid First Strand cDNA synthesis kit (Thermo Fisher Scientific, Inc.). Alteration of gene expression was performed using SensiMix SYBR kits (Bioline) and ABI PRISM 7900HT instrument (Applied Biosystems; Thermo Fisher Scientific, Inc.). Primer sequences were as follows: human PDGFB (forward, 5'-CGAATGGTCACCCGAGTTTG-3' and reverse, 5'-GAGATGCTGAGTGACCACTC-3'), human ER- $\alpha$ (forward, 5'-CGC TAC TGT GCA GTG TGC AAT-3' and reverse, 5'-CCT CAC AGG ACC AGA CTC CAT AA-3') and GAPDH as an endogenous control (forward, 5'-ATT GTT GCC ATC AAT GAC CC-3' and reverse, 5'-AGT AGA GGC AGG GAT GT-3'). Thermocycling conditions were $95^{\circ} \mathrm{C}$ for $10 \mathrm{~min}, 40$ cycles of $95^{\circ} \mathrm{C}$ for $15 \mathrm{sec}, 60^{\circ} \mathrm{C}$ for $15 \mathrm{sec}$ and $72^{\circ} \mathrm{C}$ for $15 \mathrm{sec}$. For data analysis, the raw threshold cycle $\left(\mathrm{C}_{T}\right)$ value was normalized to the housekeeping gene for each sample to obtain $\Delta \mathrm{C}_{T}$. Normalized $\Delta \mathrm{C}_{T}$ was calibrated to control cell samples to calculate $\Delta \Delta \mathrm{C}_{T}(13,14)$.

Colony-forming assays. MCF-7 and T47D breast cancer cells were plated onto 6 -well tissue culture plates $\left(2 \times 10^{3}\right.$ cells/well $)$ for the colony formation assay. After $24 \mathrm{~h}$, the cells were treated with $2 \mu \mathrm{M}$ specific inhibitors (ponatinib and sunitinib; Selleck Chemicals), followed by an additional incubation for 10 days. Subsequently, the colonies were fixed in $10 \%$ ethanol for $5 \mathrm{~min}$ at RT and stained with $0.01 \%$ crystal violet for $30 \mathrm{~min}$ at RT and observed using a CK40 inverted microscope (magnification, x20; Olympus Corporation).

MTT assay. Breast cancer MCF-7 and T47D cell lines were plated onto 96 -well tissue culture plates $\left(1 \times 10^{3}\right.$ cells/well) for the MTT assay. After $24 \mathrm{~h}$, the cells were treated with sunitinib or ponatinib at $0.3125-5.000 \mu \mathrm{M}$ concentration at $37^{\circ} \mathrm{C}$ for $48 \mathrm{~h}$. To analyze cell proliferation, equal volumes of serum-free media and MTT solution were added into each well of 96-well tissue culture plates. Following incubation at $37^{\circ} \mathrm{C}$ for $3 \mathrm{~h}$, dimethyl sulfoxide was added to completely dissolve the MTT formazan. The optical density was read at $590 \mathrm{~nm}$ using a tunable microplate reader (Spectra max 190; Molecular Devices, LLC).

Cell cycle analysis. Breast cancer MCF-7 cells ( $3 \times 10^{5}$ cells $/ 60 \mathrm{~mm}$ dish) were seeded into each cell culture dish. Following incubation for $24 \mathrm{~h}$, cells were trypsinized and washed with phosphate-buffered saline (PBS) twice. Following centrifugation ( $524 \mathrm{x} \mathrm{g}$ for $5 \mathrm{~min}$ at RT), cells were resuspended in $1 \mathrm{ml}$ PBS and fixed in $70 \%$ ethanol for $20 \mathrm{~min}$ at RT. Fixed cells were centrifuged at $524 \mathrm{xg}$ for $5 \mathrm{~min}$ and washed twice with PBS. The supernatant was discarded and cell pellets were resuspended in $1 \mathrm{ml}$ PBS with $100 \mu \mathrm{g} / \mathrm{ml}$ DNase-free RNase A (Biopure) and incubated for $30 \mathrm{~min}$ in a $37^{\circ} \mathrm{C}$ water bath. Next, $50 \mu \mathrm{g} / \mathrm{ml}$ propidium iodide (Sigma-Aldrich; Merck KGaA) was added to the cell suspension and analyzed using the FACSCalibur flow cytometer (Becton Dickinson and Company) (15).

Apoptosis assay. Apoptosis detection using Annexin V and 7-AAD was performed according to the manufacturer's 
Table I. Molecular subtypes of breast cancer cell lines.

\begin{tabular}{lccccc}
\hline Cell lines & ER & PR & HER2 & Subtype & Tumor \\
\hline MCF-7 & + & + & - & Luminal A & IDC \\
ZR75-1 & + & $+/-$ & - & Luminal A & IDC \\
BT474 & + & + & + & Luminal B & IDC \\
T47D & + & + & - & Luminal A & IDC
\end{tabular}

ER, estrogen receptor; PR, progesterone receptor; HER2, human epidermal growth factor 2 ; IDC, invasive ductal carcinoma.

protocol (Biogems Biotechnologies Inc.). As shown in Fig. 5, MCF-7 and T47D cell lines were cultured to $70 \%$ confluence, and treated with 4-OHT and/or sunitinib or ponatinib at the indicated concentration. After $48 \mathrm{~h}$, cells were harvested and washed twice with pre-cooled PBS and then resuspended in $1 \mathrm{X}$ Annexin $\mathrm{V}$ binding buffer at a concentration of $1 \times 10^{6}$ cells $/ \mathrm{ml}$. Next, $100 \mu \mathrm{l}$ of this solution was mixed with $5 \mu \mathrm{l}$ Annexin $\mathrm{V}$ and $5 \mu \mathrm{l}$ 7-AAD for $15 \mathrm{~min}$ at room temperature in the dark. The mixed solution was incubated at RT $\left(25^{\circ} \mathrm{C}\right)$ in the dark for $15 \mathrm{~min}$. Next, $400 \mu 1$ Annexin $\mathrm{V}$ binding buffer was added to each tube. Analysis was performed using the FACSCalibur flow cytometer and BD CellQuest Pro software v.6 (Becton Dickinson and Company).

Statistical analysis. Statistical significance between two groups of data was calculated using Student's t-test (two-tailed). One-way analysis of variance and Dunnett's post hoc test were used for comparisons among multiple groups. Statistical analysis was performed using GraphPad Prism 8 software (GraphPad Software, Inc.). Results are presented as the mean \pm standard error of the mean. All quoted P-values were two-tailed and $\mathrm{P}<0.05$ was considered to indicate a statistically significant difference.

\section{Results}

PDGFB expression is associated with the poor prognosis of $E R^{+}$breast cancer. In a previous study, Paulsson et al (16) reported that high stromal PDGFR $\beta$ expression was correlated with significantly shorter recurrence-free and breast cancer-specific survival rates. In the present study, the clinical significance of PDGFB expression in $\mathrm{ER}^{+}$breast cancer was analyzed using the Kaplan-Meier method. It was identified that $\mathrm{ER}^{+}$breast cancer with high PDGFB expression had poorer disease-free survival (DFS) rates $(\mathrm{P}=0.0092)$ and distant metastasis-free survival (DMFS) rates $(\mathrm{P}=0.00042)$ than those with low PDGFB expression (Fig. 1A and B). However, overall survival rates (OS; $\mathrm{P}=0.12)$ was not significantly different in $\mathrm{ER}^{+}$breast cancer (Fig. 1C). Based on these results, it was identified that the levels of PDGFB expression have a significant impact on the survival rate of patients with $\mathrm{ER}^{+}$breast cancer.

Two PDGFR inhibitors induce G0-G1 phase cell cycle arrest and inhibit the growth of $\mathrm{ER}^{+}$breast cancer cells. Four ER- $\alpha^{+}$ breast cancer cells were selected to study the biological function of PDGFB. The characteristics of these breast cancer cells are described in Table I (17). The basal level of PDGFB protein (Fig. 2A) and mRNA (Fig. 2B) expression was noted in all the ER- $\alpha^{+}$breast cancer cells.

Next, the effect of two PDGFR inhibitors on cell proliferation in breast cancer MCF-7 cells was investigated. Fig. 3A demonstrates the structure of ponatinib and sunitinib. As shown in Fig. 3B, cell viability was decreased by ponatinib or sunitinib in a dose-dependent manner. The $\mathrm{IC}_{50}$ value for sunitinib and ponatinib was 1.45 and $4.51 \mu \mathrm{M}$, respectively (Fig. 3B). Furthermore, the influence of the two PDGFR inhibitors on the cell cycle was investigated. Notable, the two inhibitors induced G0-G1 phase cell cycle arrest (Fig. 3C). Additionally, cell proliferation was suppressed by $2 \mu \mathrm{M}$ ponatinib or sunitinib (Fig. 3D). Furthermore, cell growth by specific PDGFR- $\alpha$ and PDGFR- $\beta$ antibodies was decreased (Fig. S1A). It was evident that the two PDGFR inhibitors suppressed cell proliferation through the G0/G1 phase cell cycle arrest.

Two PDGFR inhibitors suppress MMP-1 expression through the inhibition of STAT-3 and ERK pathway. Degradation and rearrangement of the extracellular matrix by MMPs is a prerequisite for tumor invasion and metastasis (18). Therefore, the effects of the two PDGFR inhibitors on MMP-1 expression, which serves an important role in cell migration and invasion, were investigated. Although neither sunitinib nor ponatinib influenced the expression of ER- $\alpha$ (Fig. 4A), the two PDGFR inhibitors completely suppressed the expression of MMP-1 mRNA (Fig. 4B). Sunitinib $(2 \mu \mathrm{M})$ decreased the level of MMP-1 mRNA expression by $0.36 \pm 0.06$-fold compared with the control level, while ponatinib decreased the expression by $0.30 \pm 0.11$-fold compared with the control level (Fig. 4B). Under similar conditions, the expression level of MMP-1 protein was decreased by the two PDGFR inhibitors (Fig. 4C). Furthermore, the downstream signaling pathway of PDGFR was investigated. As demonstrated in Fig. 4C, sunitinib and ponatinib completely inhibited phosphorylation of STAT-3 and ERK. Therefore, the MCF-7 cells were treated with specific inhibitors (UO126, MEK inhibitor; Stattic, STAT-3 inhibitor) for $24 \mathrm{~h}$. Levels of MMP-1 mRNA expression were significantly decreased by UO126 treatment (Fig. 4D). In addition, MMP-1 expression was analyzed using a specific PDGFR- $\beta$ antibody (Fig. S1B). As expected, the basal level of MMP-1 expression was decreased by PDGFR- $\beta$ antibody treatment (Fig. S1B). The results revealed that the two PDGFR inhibitors downregulated MMP-1 expression by inhibiting the MEK/ERK pathway.

The combined effect of sunitinib or ponatinib with tamoxifen. The combined effect of sunitinib or ponatinib with tamoxifen on ER- $\alpha^{+}$breast cancer cells was investigated. Using conditioned media with charcoal-stripped FBS which removes non-polar material such as growth factors, hormones and cytokines, cells were treated with 4-OHT at the indicated concentration. As shown in Fig. 5A, cell viability was decreased by nearly half at a concentration of $15 \mu \mathrm{M} 4-\mathrm{OHT}$. In addition, when sunitinib or ponatinib were combined with 4-OHT, cell death was accelerated in MCF-7 
A

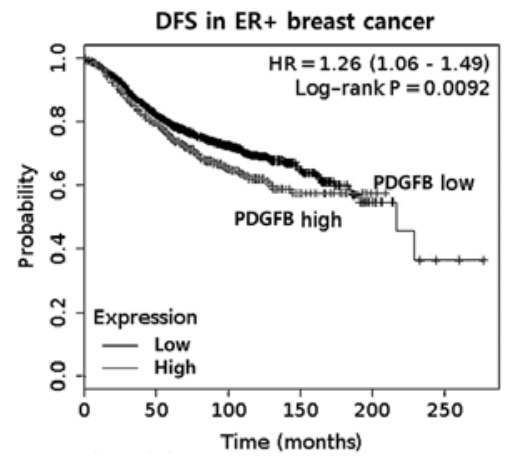

B

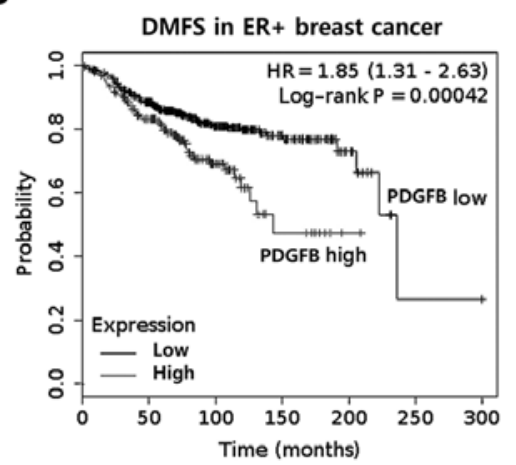

C

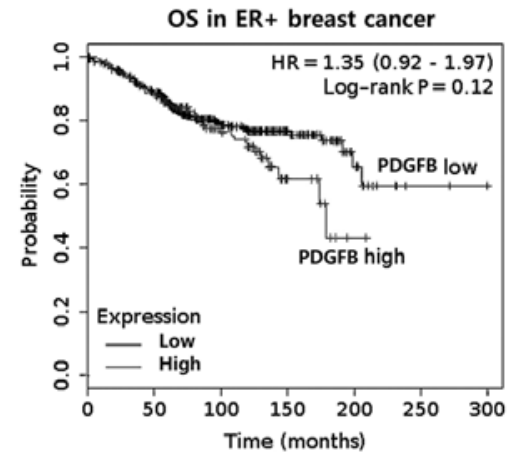

Figure 1. Association between PDGFB expression and survival rate in $\mathrm{ER}^{+}$breast cancer. (A) DFS. (B) DMFS. (C) OS. PDGFB, platelet-derived growth factor B; $\mathrm{ER}^{+}$, estrogen receptor-positive; DFS, disease-free survival; DMFS, distant metastasis-free survival; OS, overall survival; HR, hazards ratio.

A

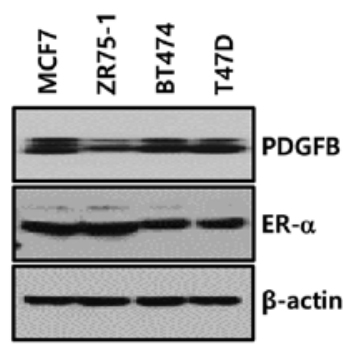

B

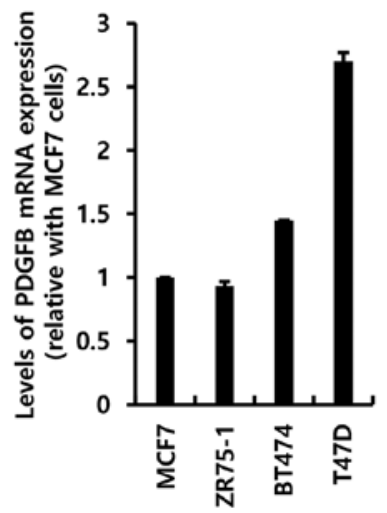

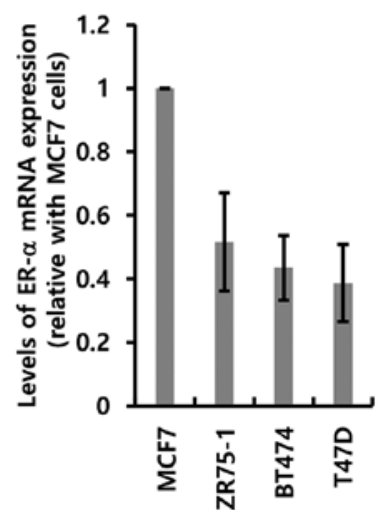

C MCF7

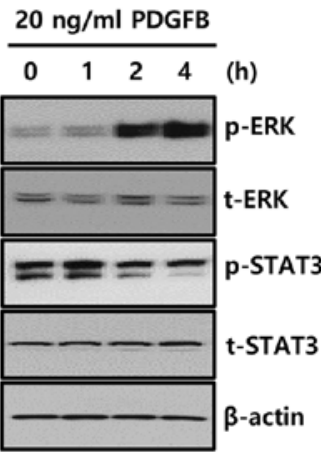

T47D

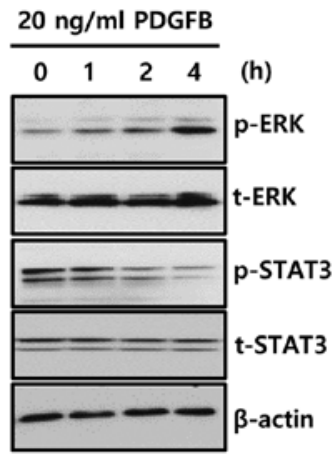

Figure 2. The expression of PDGFB and ER- $\alpha$ in breast cancer ER ${ }^{+}$cell lines. (A) Levels of PDGFB, ER- $\alpha$ and $\beta$-actin expression were analyzed by western blotting. (B) Levels of PDGFB and ER- $\alpha$ mRNA expression were analyzed by reverse transcription-quantitative polymerase chain reaction. (C) Levels of p-, t-ERK, STAT3, and $\beta$-actin expression were analyzed by western blotting. Results are representative of three independent experiments. PDGFB, platelet-derived growth factor $\mathrm{B}$; $\mathrm{ER}^{+}$, estrogen receptor-positive.

and T47D cells (Fig. 5A). These results were verified again by the colony-forming assay (Fig. 5B). The colony size and number decreased significantly when the drug was combined with sunitinib or ponatinib. Finally, the expression levels of PARP-1 and procaspase- 3 were measured for the detection of apoptotic cell death in MCF-7 and T47D cells. The cleaved forms of PARP-1 and caspase-3 increased in response to treatment with 4-OHT, while a decrease in the levels of pro-caspase-3 was observed (Fig. 5C). The cleaved forms of PARP-1 and caspase- 3 were significantly increased upon combined treatment of 4-OHT with sunitinib or ponatinib while the levels of procaspase-3 were decreased in MCF-7 and T47D cells (Fig. 5C). Furthermore, apoptotic cell death was analyzed using FACS. As expected, when sunitinib or ponatinib were combined with 4-OHT, apoptotic cell death (Q2, late apoptosis; Q4, early apoptosis) was significantly increased in MCF-7 and T47D cells (Fig. 5D). Based on these results, it was revealed that ER- $\alpha$ downregulation by EGFR 
A

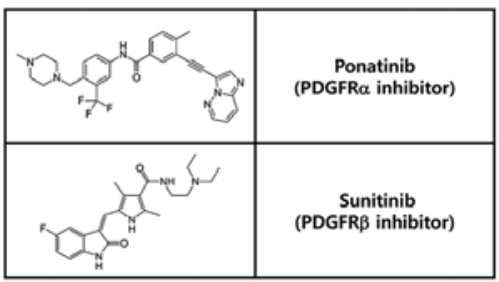

B

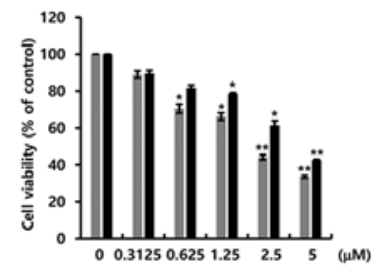

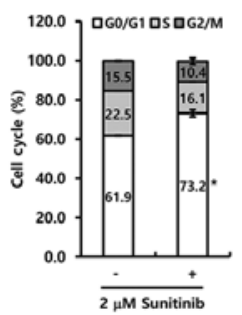

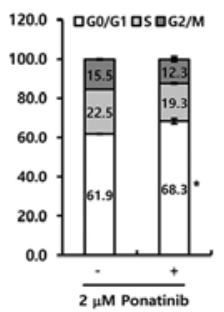

D

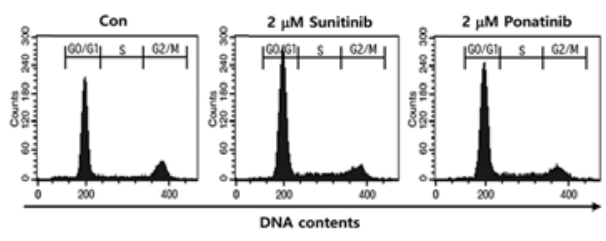

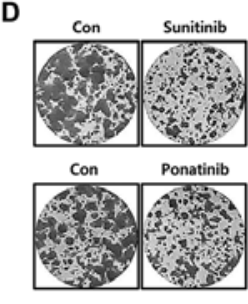

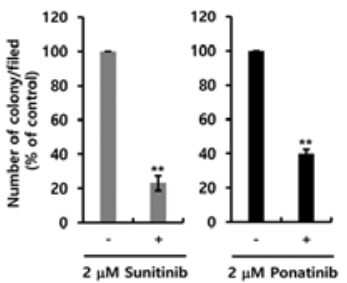

Figure 3. PDGFR- $\alpha$ and - $\beta$ inhibitors induce cell cycle arrest in breast cancer MCF-7 cell lines. (A) The chemical structures of ponatinib and sunitinib. (B) Cell viabilities were analyzed by MTT assay. (C) Changes in the cell cycle were analyzed by flow cytometry. (D) Cell proliferation was analyzed by colony formation assay and MTT assay. Results are representative of three independent experiments. Values are represented as the mean \pm standard error of the mean. ${ }^{*} \mathrm{P}<0.05,{ }^{* *} \mathrm{P}<0.01$ vs. (-). PDGFR, platelet-derived growth factor receptor.

A

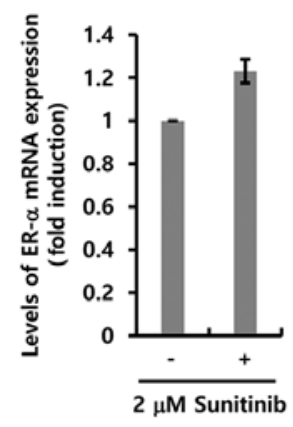

B

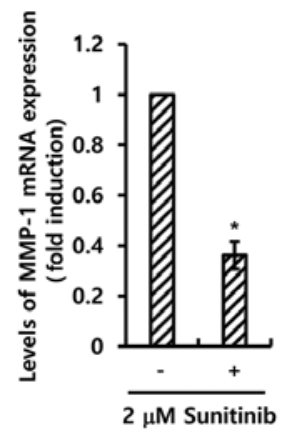

C

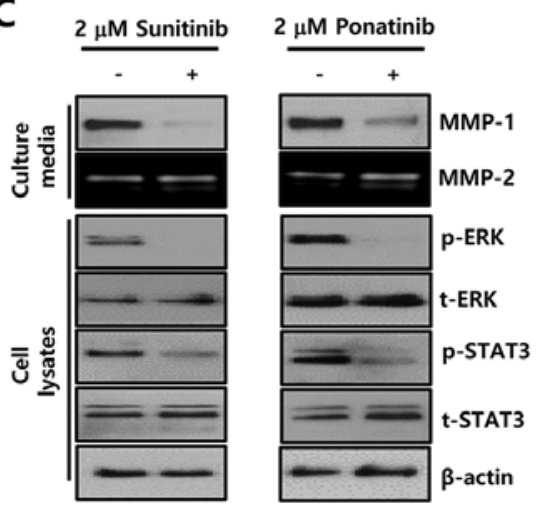

D

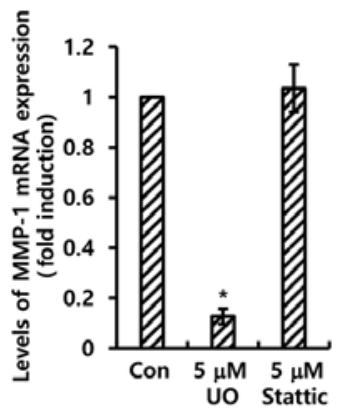

E

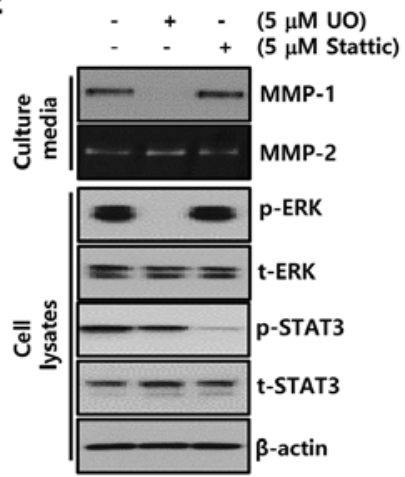

Figure 4. PDGFR- $\alpha$ and $-\beta$ inhibitors suppress MMP-1 expression through the inhibition of STAT3 and ERK activities in breast cancer MCF-7 cell lines. (A and B) Levels of ER- $\alpha$ and MMP-1 mRNA expression were analyzed by reverse transcription-quantitative polymerase chain reaction. (C) Levels of MMP-1, ER- $\alpha$, p-STAT3, p-ERK, t-STAT3 and t-ERK expression were analyzed by western blotting. (D and E) Levels of MMP-1 mRNA and protein expression by specific inhibitors were analyzed by reverse transcription-quantitative polymerase chain reaction and western blotting, respectively. Results are representative of three independent experiments. Values are represented as the mean \pm standard error of the mean. ${ }^{*} \mathrm{P}<0.05$ vs. (-). PDGFR, platelet-derived growth factor receptor; MMP, matrix metalloproteinase; ER- $\alpha$, estrogen receptor- $\alpha$.

ligands contributed toward acquired tamoxifen resistance. Inhibition by the two PDGFR inhibitors synergistically increased the pharmacological effects of tamoxifen in ER- $\alpha^{+}$ breast cancer. 
A

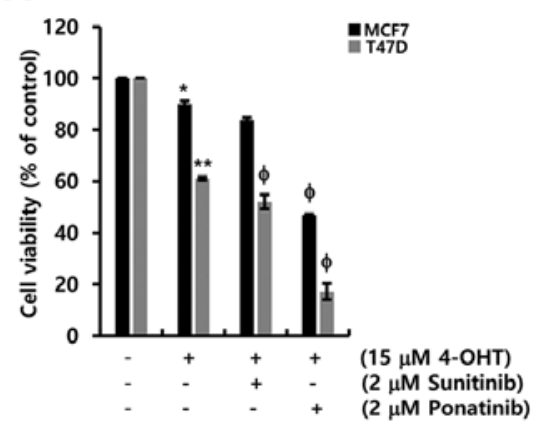

B

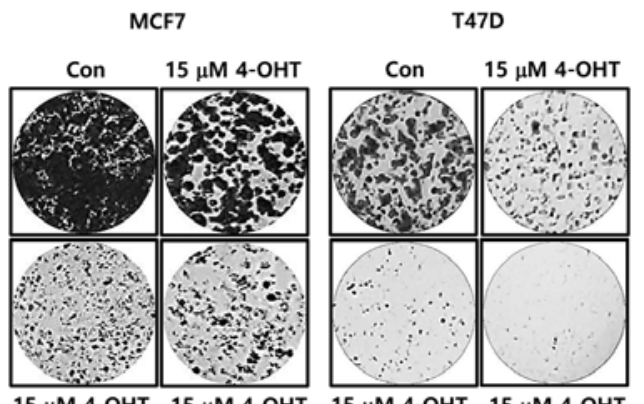

$15 \mu \mathrm{M} 4-\mathrm{OHT} \quad 15 \mu \mathrm{M} 4-\mathrm{OHT} 15 \mu \mathrm{M} 4-\mathrm{OHT} \quad 15 \mu \mathrm{M}$ 4-OHT $2 \mu \mathrm{M}$ Sunitinib $2 \mu \mathrm{M}$ Ponatinib $2 \mu \mathrm{M}$ Sunitinib $2 \mu \mathrm{M}$ Ponatinib
C
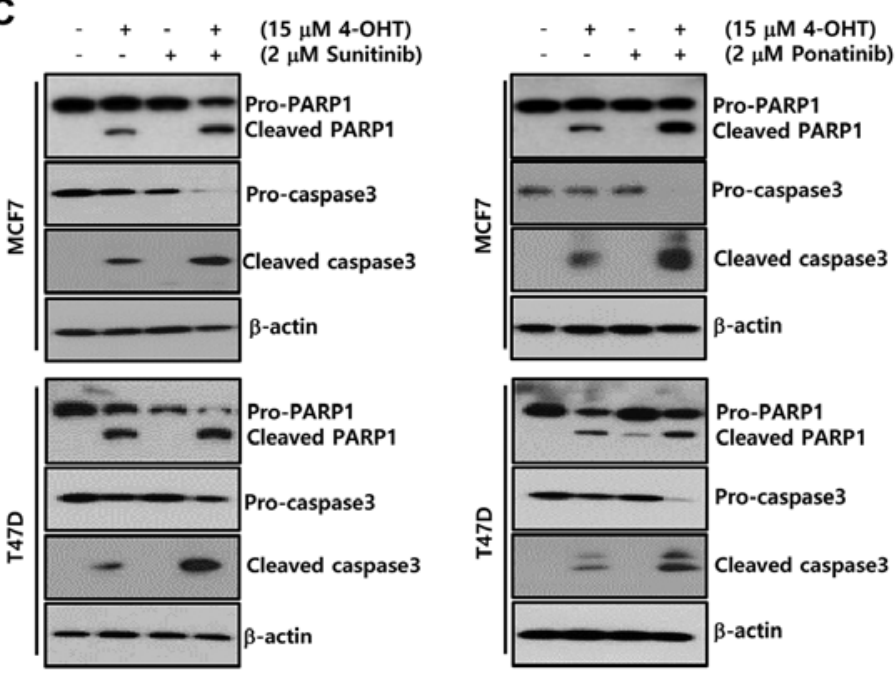

D

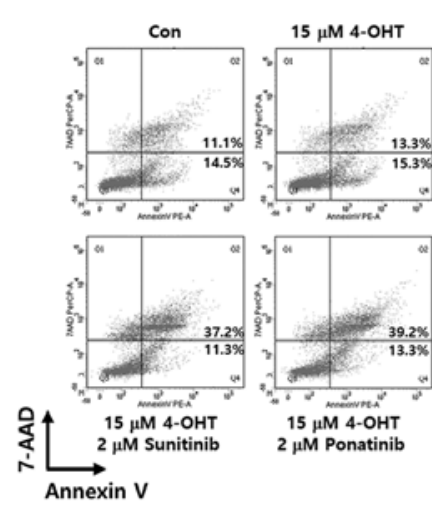

MCF7

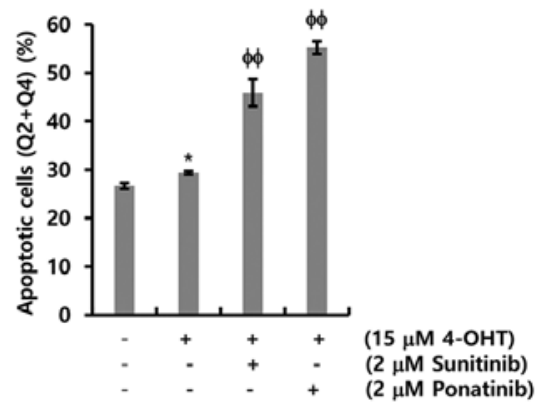

T47D
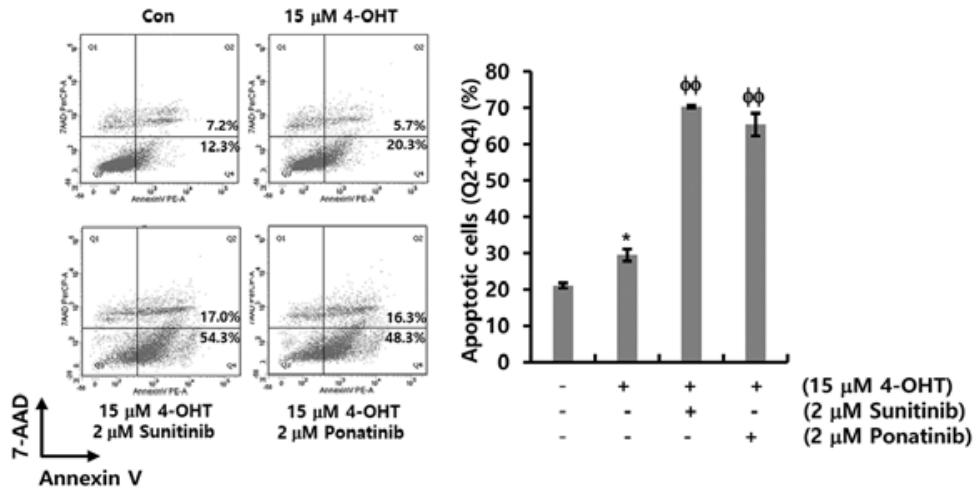

Figure 5. PDGFR- $\alpha$ and $-\beta$ inhibitors synergistically enhance the pharmacological effect of $4-\mathrm{OHT}$ in $\mathrm{ER}^{+}$breast cancer cell lines. (A) Cell viabilities in the presence of 4-OHT were analyzed by MTT assay. (B) Cell proliferation by two inhibitors and/or 4-OHT was analyzed by colony formation assay. (C) Levels of PARP-1, pro-, cleaved-caspase-3 and $\beta$-actin expression were analyzed by western blotting. (D) Apoptotic cell death was analyzed by FACS (Q2, late apoptosis; Q4, early apoptosis). Results are representative of three independent experiments. Values are represented as the mean \pm standard error of the mean. $\mathrm{P}<0.05$, ${ }^{* * *} \mathrm{P}<0.01$ vs. Con. ${ }^{\phi} \mathrm{P}<0.05,{ }^{\phi}{ }^{\phi} \mathrm{P}<0.01$ vs. $4-\mathrm{OHT}$ treated. PDGFR, platelet-derived growth factor receptor; $\mathrm{ER}^{+}$, estrogen receptor-positive; Con, control.

\section{Discussion}

At present, there is not yet a complete understanding of the association between the expression of PDGFB and the survival of patients with $\mathrm{ER}^{+}$breast cancer. The present study aimed to analyze the $\mathrm{ER}^{+}$breast cancer survival rate following the expression of PDGFB. In previous studies, the prognosis of patients with low PDGF-BB improved the progression-free survival and overall survival compared with that of the others in numerous human tumors, including colorectal cancer, pancreatic cancer, esophageal cancer and liver cancer (19-22). Additionally, aberrant PDGFB expression is associated with the vascular mechanism in $4 \mathrm{~T} 1$ cancer cells in vivo, but not with the direct proliferative promotion of breast cancer cells (23). Consistent with these reports, the survival rates of patients with $\mathrm{ER}^{+}$breast cancer based on PDGFB expression was analyzed using the Kaplan-Meier plotter. Consequently, it was revealed that the expression of PDGFB is directly associated 
with the DFS and DMFS in $\mathrm{ER}^{+}$breast cancer. Therefore, it was demonstrated that the downregulation of PDGFB or the inhibition of the PDGFB/PDGFR signaling pathway may be a novel strategy for $\mathrm{ER}^{+}$breast cancer treatment.

PDGF-BB facilitates the stem-like characteristics of $\mathrm{OV}^{+}$ cancer stem-like cells (CSCs) by enhancing YAP stability (24). PDGFB downregulation by PDGFB shRNA suppresses cell proliferation and invasion by blocking the PI3K/AKT pathway in esophageal squamous cell carcinoma cells (21). Autocrine PDGF/PDGFR signaling contributes toward the maintenance of epithelial-mesenchymal transition (EMT) through the activation of STAT1 in murine and human mammary carcinoma cell lines (25). Consistent with the published data, the results of the present study demonstrated that the phosphorylation of ERK and STAT3 is significantly decreased by the two PDGFR inhibitors, ponatinib (PDGFR- $\alpha$ inhibitor) and sunitinib (PDGFR- $\beta$ inhibitor). MMP-1 expression, which serves an important role in cell invasion and migration, was revealed to be completely downregulated by the two inhibitors. In addition, these inhibitors induced the G0/G1 phase arrest and suppressed cell proliferation in $\mathrm{ER}^{+}$breast cancer cells. Consequently, it was demonstrated that accurate employment of sunitinib and ponatinib will be of significance in curbing the growth and metastasis of $\mathrm{ER}^{+}$breast cancer.

Aberrant PDGFB induction decreases the sensitivity to ionizing radiation in esophageal squamous cell carcinoma cells and promotes the $c i s$-platinum resistance of $\mathrm{OV}^{+} \mathrm{CSCs}$ in bladder cancer (21,24).PDGF-BB enhances c-myc expression and decreases the melphalan sensitivity of multiple myeloma (26). In addition, Wang etal (23) reported that metformin greatly decreases PDGFB protein levels and improves the chemosensitivity against cyclophosphamide in $4 \mathrm{~T} 1$ cells in vivo. PDGFB/PDGFR $\beta$ axis is involved in imparting resistance to antiangiogenic therapy in renal cancer (27). Although sunitinib and ponatinib did not affect apoptotic cell death and ER- $\alpha$ expression, it was evident that combined treatment of tamoxifen with the inhibitors was more effective than the treatment with tamoxifen alone in $\mathrm{ER}^{+}$ breast cancer cells. Additionally, the present study could have aimed to verify the pharmacological effects of tamoxifen and/or sunitinib or ponatinib through normal breast cells. However, only the effectiveness of breast cancer cells was verified as no normal breast cells were available. It is revealed that the blockage of the PDGFB/PDGFR axis is one of the alternatives to overcome tamoxifen resistance.

In conclusion, the clinical significance of PDGFB expression and the pharmacological effect of PDGFR inhibitors was investigated in $\mathrm{ER}^{+}$breast cancer cells. It was demonstrated that PDGFB is one of the factors that greatly affect the survival rate in $\mathrm{ER}^{+}$breast cancers. Ponatinib and sunitinib induced cell cycle arrest and completely suppressed cell proliferation. Furthermore, it was observed that the combined therapy of tamoxifen with PDGFR inhibitors induced effectual cell death than treatment with tamoxifen alone. Consequently, based on these findings, it was suggested that the possibility of combination treatment employing PDGFR inhibitors as an effective treatment strategy for $\mathrm{ER}^{+}$breast cancer in the future.

\section{Acknowledgements}

Not applicable.

\section{Funding}

The present study was supported by the Basic Science Research Program through the National Research Foundation of Korea (NRF) funded by the Ministry of Education (grant no. 2016R1D1A1B01010508) and was supported by the MSIT (Ministry of Science and ICT), Korea, under the ICT Creative Consilience program (grant no. IITP-2020-0-01821) supervised by the IITP (Institute for Information \& communications Technology Planning \& Evaluation).

\section{Availability of data and materials}

The datasets used and/or analyzed during the current study are available from the corresponding author on reasonable request.

\section{Authors' contributions}

SK and JEL contributed to the experiment design, analyzed the results and wrote the manuscript. SK, DY, YJ, SYY, and SAK performed the experiments and analyzed the results. SK, DY, YJ, SYY, SAK and JEL confirmed the authenticity of the raw data. All authors have read and approved the manuscript.

\section{Ethics approval and consent to participate}

Not applicable.

\section{Patient consent for publication}

Not applicable.

\section{Competing interests}

The authors declare that they have no competing interests.

\section{References}

1. Perou CM, Sørlie T, Eisen MB, van de Rijn M, Jeffrey SS, Rees CA, Pollack JR, Ross DT, Johnsen H, Akslen LA, et al: Molecular portraits of human breast tumours. Nature 406: 747-752, 2000

2. Osborne CK: Tamoxifen in the treatment of breast cancer. N Engl J Med 339: 1609-1618, 1998.

3. Early Breast Cancer Trialists' Collaborative Group (EBCTCG): Effects of chemotherapy and hormonal therapy for early breast cancer on recurrence and 15-year survival: An overview of the randomised trials. Lancet 365: 1687-1717, 2005.

4. Fredriksson L, Li H and Eriksson U: The PDGF family: Four gene products form five dimeric isoforms. Cytokine Growth Factor Rev 15: 197-204, 2004.

5. Ostman A: PDGF receptors-mediators of autocrine tumor growth and regulators of tumor vasculature and stroma. Cytokine Growth Factor Rev 15: 275-286, 2004.

6. Bergsten E, Uutela M, Li X, Pietras K, Ostman A, Heldin CH, Alitalo K and Eriksson U: PDGF-D is a specific, protease-activated ligand for the PDGF beta-receptor. Nat Cell Biol 3: 512-516, 2001.

7. Kazlauskas A: PDGFs and their receptors. Gene 614: 1-7, 2017.

8. Heldin CH, Ostman A and Rönnstrand L: Signal transduction via platelet-derived growth factor receptors. Biochim Biophys Acta 1378: F79-F113, 1998.

9. Carvalho I, Milanezi F, Martins A, Reis RM and Schmitt F: Overexpression of platelet-derived growth factor receptor alpha in breast cancer is associated with tumour progression. Breast Cancer Res 7: R788-R795, 2005. 
10. Györffy B, Lanczky A, Eklund AC, Denkert C, Budczies J, Li Q and Szallasi Z: An online survival analysis tool to rapidly assess the effect of 22,277 genes on breast cancer prognosis using microarray data of 1,809 patients. Breast Cancer Res Treat 123: 725-731, 2010.

11. Kim S, You D, Jeong Y, Yu J, Kim SW, Nam SJ and Lee JE: Berberine down-regulates IL-8 expression through inhibition of the EGFR/MEK/ERK pathway in triple-negative breast cancer cells. Phytomedicine 50: 43-49, 2018.

12. Jeon M, Han J, Nam SJ, Lee JE and Kim S: Elevated IL-1 $\beta$ expression induces invasiveness of triple negative breast cancer cells and is suppressed by zerumbone. Chem Biol Interact 258: 126-133, 2016.

13. Hosaka K, Yang Y, Seki T, Fischer C, Dubey O, Fredlund E, Hartman J, Religa P, Morikawa H, Ishii Y, et al: Pericyte-fibroblast transition promotes tumor growth and metastasis. Proc Natl Acad Sci USA 113: E5618-E5627, 2016.

14. Kim S, Lee J, Oh SJ, Nam SJ and Lee JE: Differential effect of EGFR inhibitors on tamoxifen-resistant breast cancer cells. Oncol Rep 34: 1613-1619, 2015.

15. Kim S, Lee J, Jeon M, Nam SJ and Lee JE: Elevated TGF- $\beta 1$ and $-\beta 2$ expression accelerates the epithelial to mesenchymal transition in triple-negative breast cancer cells. Cytokine 75 $151-158,2015$

16. Paulsson J, Sjöblom T, Micke P, Pontén F, Landberg G, Heldin CH, Bergh J, Brennan DJ, Jirström K and Ostman A: Prognostic significance of stromal platelet-derived growth factor beta-receptor expression in human breast cancer. Am J Pathol 175: 334-341, 2009.

17. Dai X, Cheng H, Bai Z and Li J: Breast Cancer Cell Line Classification and Its Relevance with Breast Tumor Subtyping. J Cancer 8: 3131-3141, 2017.

18. Stetler-Stevenson WG, Aznavoorian S and Liotta LA: Tumor cell interactions with the extracellular matrix during invasion and metastasis. Annu Rev Cell Biol 9: 541-573, 1993

19. McCarty MF, Somcio RJ, Stoeltzing O, Wey J, Fan F, Liu W, Bucana $C$ and Ellis LM: Overexpression of PDGF-BB decreases colorectal and pancreatic cancer growth by increasing tumor pericyte content. J Clin Invest 117: 2114-2122, 2007.
20. Nakamura Y, Tanaka F, Yoshikawa Y, Mimori K, Inoue H, Yanaga $\mathrm{K}$ and Mori M: PDGF-BB is a novel prognostic factor in colorectal cancer. Ann Surg Oncol 15: 2129-2136, 2008.

21. Er P, Qian D, Zhang W, Zhang B, Wei H, Zhang T, Chen X, Wang Y, Zhao J, Wang Q, et al: The expression of PDGF-BB predicts curative effect in locally advanced esophageal squamous cell carcinoma treated by radiotherapy. Aging (Albany NY) 12: 6586-6599, 2020

22. Fingas CD, Bronk SF, Werneburg NW, Mott JL, Guicciardi ME, Cazanave SC, Mertens JC, Sirica AE and Gores GJ: Myofibroblast-derived PDGF-BB promotes Hedgehog survival signaling in cholangiocarcinoma cells. Hepatology 54: 2076-2088, 2011.

23. Wang JC, Li GY, Wang B, Han SX, Sun X, Jiang YN, Shen YW, Zhou C, Feng J, Lu SY, et al: Metformin inhibits metastatic breast cancer progression and improves chemosensitivity by inducing vessel normalization via PDGF-B downregulation. J Exp Clin Cancer Res 38: 235, 2019.

24. Wang KJ, Wang C, Dai LH, Yang J, Huang H, Ma XJ, Zhou Z, Yang ZY, Xu WD, Hua MM, et al: Targeting an Autocrine Regulatory Loop in Cancer Stem-like Cells Impairs the Progression and Chemotherapy Resistance of Bladder Cancer. Clin Cancer Res 25: 1070-1086, 2019.

25. Jechlinger M, Sommer A, Moriggl R, Seither P, Kraut N, Capodiecci P, Donovan M, Cordon-Cardo C, Beug $\mathrm{H}$ and Grünert S: Autocrine PDGFR signaling promotes mammary cancer metastasis. J Clin Invest 116: 1561-1570, 2006.

26. Greco C, D'Agnano I, Vitelli G, Vona R, Marino M, Mottolese M, Zuppi C, Capoluongo E and Ameglio F: c-MYC deregulation is involved in melphalan resistance of multiple myeloma: Role of PDGF-BB. Int J Immunopathol Pharmacol 19: 67-79, 2006.

27. CumpănasAA,CimpeanAM,FericianO,CeausuRA,SarbS,Barbos V, Dema A and Raica M: The Involvement of PDGF-B/PDGFR $\beta$ Axis in the Resistance to Antiangiogenic and Antivascular Therapy in Renal Cancer. Anticancer Res 36: 2291-2295, 2016.

This work is licensed under a Creative Commons Attribution-NonCommercial-NoDerivatives 4.0 International (CC BY-NC-ND 4.0) License. 